\title{
Kajian Awal Adsorben Abu Kayu Terhadap Methylene Blue
}

\author{
HR Yuliani ${ }^{1, \text { a }}$, Hartono Tri ${ }^{1}$, Puspita $\mathrm{S}^{1}$, Juliati ${ }^{1}$, Musfirah A.A ${ }^{1}$, Isma A.N.P.Z ${ }^{1}$, Ida A.I ${ }^{1}$ \\ ${ }^{1}$ Dosen, T. Kimia, Politeknik Negeri Ujung Pandang, Jl. Perintis Kemerdekaan KM 10, Makassar, 90112, Indonesia \\ ayulianihr@poliupg.ac.id
}

\begin{abstract}
This study aim the adsorption capacity of wood ash adsorbent from Makassar coto wood (ACM) and wood ash in the air cooking (AMA) of the blue methylene solution and its characteristics. ACM is activated by $\mathrm{NaOH} 3 \mathrm{M}$ and $\mathrm{NaCl} 0.85$ $M$, to improve its performance as an adsorbent. ACM without permission and activation as well as AMA of 0.25 grams were tested against $50 \mathrm{ml}$ of methyl blue with concentrations of $\mathbf{1 0}$, 20, 30, 40 and $50 \mathrm{ppm}$. Adsorption runs for 1.5 hours using a shaker at a speed of 500 rom. Adsorbent and adsorbate use filter paper then the absorbance of the filtrate is taken to determine the equilibrium concentration (Ce) of methylene blue. The maximum adsorbent capacity (qm) is determined using the Langmuer equation for the administrator's ACM adorbent type and without activation with AMA. Other tests consisted of adsorbent characteristics consisting of ACM and AMA compositions. The results of the study showed differences, namely ACA having a composition of $\mathbf{2 8 . 1 5 \%}$ Silica (Si), 20.86\% Ca and AMA namely $30.68 \% \mathrm{Si}, \mathbf{1 5 . 2 9 \%}$ Ca. The maximum adsorption capacity (qm) of ACM is $\mathbf{1 2 . 3 7}$ $\mathrm{mg} / \mathrm{g}$ and for AMA is $10.29 \mathrm{mg} / \mathrm{g}$. Activation of $3 \mathrm{M} \mathrm{NaOH}$ ACM has an adsorption capacity (qm) of $13.01 \mathrm{mg} / \mathrm{g}$ and activation of $0.85 \mathrm{M} \mathrm{NaCl}$ which is $15.15 \mathrm{mg} / \mathrm{g}$.
\end{abstract}

Keywords--Wood Ash, Methyl Blue, Abu Coto Makassar, Water Cook Ash, Activation

\begin{tabular}{l}
\hline \multicolumn{4}{c}{ Abstrak--Penelitian ini bertujuan } & \multicolumn{2}{c}{ mengetahui } \\
kemampuan adsorpsi dari adsorben abu kayu hasil \\
pembakaran kayu coto makassar dan abu kayu pada \\
pemasakan air terhadap larutan methylene blue dan \\
karateristiknya. Abu Coto Makassar (ACM) diaktivasi secara \\
basa (NaOH) 3M dan garam (NaCl) 0.85 M, guna \\
meningkatkan kinerja sebagai adsorben. ACM dan ACM \\
aktivasi serta AMA sebanyak 0.25 gram diujikan terhadap 50 \\
ml methyl blue dengan konsentrasi 10, 20, 30, 40 dan 50 ppm. \\
Adsorpsi berlangsung selama 1.5 jam menggunakan shaker \\
pada kecepatan 500 rom. Adsorben dan adsorbat dipisahkan
\end{tabular}

menggunakan kertas saring kemudian filtrate diukur absorbansinya untuk mentukan konsentrasi setimbang (Ce) methylene blue. Kapasitas maksimum adsorben (qm) ditentukan menggunakan persamaan langmuer untuk jenis adorben ACM aktivasi dan tanpa aktivasi serta AMA. Pengujian lain berupa karateristik adsorben berupa komposisi ACM dan AMA. Hasil penelitian menunjukkan perbedaan menonjolkan yaitu ACA memiliki komposisi 28,15\% Silika (Si), 20.86\% Ca dan AMA yaitu 30.68\% Si, $15.29 \%$ Ca. Kapasitas adsorpsi maksimum (qm) ACM $12.37 \mathrm{mg} / \mathrm{g}$ dan sebesar dan AMA yaitu $10.29 \mathrm{mg} / \mathrm{g}$. Aktivasi ACM NaOH 3M memiliki kapasitas adsorpsi (qm) sebesar $13.01 \mathrm{mg} / \mathrm{g}$ dan aktivasi $\mathrm{NaCl} 0.85 \mathrm{M}$ yaitu $15.15 \mathrm{mg} / \mathrm{g}$.

Kata Kunci--Abu Kayu, Methyl Blue, Abu Coto Makassar, Abu Masak Air, Aktivasi

\section{Pendahuluan}

Coto makassar merupakan makanan tradisional Sulawesi Selatan yang direkomendasi buat siapa saja ke Makassar. Makanan ini dimasak menggunakan tungku dengan bahan bakar berasal dari kayu. Masyarakat di wilayah pedesaan sekitar sudiang menggunakan kayu sebagai bahan bakar, kayu hasil pembakaran ini menghasilkan abu dikenal sebutan abu gosok. Abu ini oleh masyarakat dimanfaatkan sebagai pembersih peralatan rumah tangga. Komposisi abu gosok mengandung (1) oksida yaitu $\mathrm{Al}_{2} \mathrm{O}_{3}, \mathrm{CaO}$, $\mathrm{Fe}_{2} \mathrm{O}_{3}, \mathrm{MnO}_{2}, \mathrm{P}_{2} \mathrm{O}_{5}, \mathrm{~K}_{2} \mathrm{O}, \mathrm{SiO}_{2}$, (2) karbonat berupa $\mathrm{Na}_{2} \mathrm{CO}_{3}, \mathrm{~K}_{2} \mathrm{CO}_{3}$ dan (3) bikarbonat yakni $\mathrm{NaHCO}_{3}$ (backing soda), [1]. Senyawa-senyawa yang terkandung dalam abu kayu yaitu kalsium 3,56\%, 
magnesium $0,97 \%$, natrium $0,52 \%$, kalium $4,77 \%$ dan silika 7,77\%. [2] mengatakan abu kayu memiliki kebasaan tertinggi dibandingkan abu pasar, abu bambu, abu sekam. Sifat ini akan mempengaruhi penyerapan mineral dari abu ke dalam telur itik selama proses pengasinan. Abu kayu mengandung 5,319,68\% kalsium oksida [3]. Menurut [4] kandungan abu kayu silika $88.66 \%$, Ca $0.75 \%$ dan mineral lainnya. Berdasarkan analisis XRD komposisi ACA dan AMA [5] ditunjukkan Tabel 1.

Tabel 1. Komposisi ACM dan AMA

\begin{tabular}{cccccccc}
\hline & \multicolumn{7}{c}{ Komposisi } \\
\cline { 2 - 9 } $\begin{array}{c}\text { Jenis } \\
\text { Abu }\end{array}$ & $\begin{array}{c}\mathrm{Si} \\
(\%)\end{array}$ & $\begin{array}{c}\mathrm{Al} \\
(\%)\end{array}$ & $\begin{array}{c}\mathrm{Fe} \\
(\%)\end{array}$ & $\begin{array}{c}\mathrm{Ca} \\
(\%)\end{array}$ & $\begin{array}{c}\mathrm{Mg} \\
(\%)\end{array}$ & $\begin{array}{c}\mathrm{K} \\
(\%)\end{array}$ & $\begin{array}{c}\mathrm{S} \\
(\%)\end{array}$ \\
\hline Abu Coto & 28.11 & 3.30 & 5.76 & 20.86 & 3.30 & 4.90 & 1.35 \\
AMA & 30.68 & 5.03 & 6.17 & 15.29 & 3.60 & 8.29 & 1.38 \\
\hline
\end{tabular}

Kandungan silika, karbonat dalam abu gosok khusus abu kayu bakar menjadi dasar material ini dapat menjadi adsorben. Beberapa jenis bahan yang digunakan sebagai adsorbent yaitu material organik dan material anorganik. Adsorben yang berasal dari material organik yaitu karbon aktif dan adsorben berbahan polimer. Adsorben berbahan anorganik antara lain alumina, silica, zeolite dan lempung terpilar [6]. Penentuan kemampuan penjerap adsorben diaplikasikan ke adsorbat dikenal dengan proses adsorpsi. Pada proses ini, dua hal penting yakni adsorben (material penjerap) dan adsorbat (material dijerap) umumnya berupa larutan. Adsorpsi adalah proses penjerapan solute dari fluida ke permukaan aktif padatan, fenomena ini terjadi karena terdapat gaya-gaya yang tidak seimbang pada batas antar permukaan. Metode ini berkaitan dengan proses akumulasi atau pemusatan substansi adsorbat pada permukaan adsorben.

\section{Adsorben}

Adsorben merupakan material yang digunakan untuk menjerap adsorbat dalam proses adsorpsi. Kriteria kualitas adsorben untuk aplikasi mencakup beberapa aspek antara lain : kapasitas, selektivitas, regenerasi, kinetik, compatibilitas dan biaya [5]. Kapasitas adsorpsi merupakan karakteristik yang paling penting dari suatu adsorben. Secara sederhana kapasitas dinyatakan sebagai jumlah adsorbat yang dapat dijerap oleh adsorben per satuan massa adsorben. Kapasitas adsorpsi tergantung dari konsentrasi fasa fluida, temperatur dan kondisi lain terutama keadaan awal adsorben. Pada penelitian ini abu kayu merupakan adsorben yang berasal dari kayu hasil pembakaran pemasakan coto makassar dan kayu pemasak air minum. Komposisi kedua abu ditunjukkan pada Tabel 1, Analisis XRD Yuliani HR (24 Mei 2019).

2. Adsorbat (Methylene Blue)

Methylene blue merupakan senyawa hidrokarbon aromatik yang beracun dengan rumus kimia $\mathrm{C}_{16} \mathrm{H}_{18} \mathrm{ClN}_{3} \mathrm{~S}$, dikenal sebagai zat warna kationik dengan daya adsorpsi sangat kuat. Pada umumnya methylene blue digunakan sebagai pewarna sutra, wool, tekstil, kertas, peralatan kantor dan kosmetik. Senyawa ini berbentuk kristal berwarna hijau gelap. Zat warna methylene blue dalam air atau alkohol akan menghasilkan larutan berwarna biru. Methylene blue memiliki berat molekul 319.86 $\mathrm{gr} / \mathrm{mol}$, dengan titik lebur di $105^{\circ} \mathrm{C}$ dan daya larut sebesar 4.36 x $104 \mathrm{mg} / \mathrm{L}$ [7].

Methylene biru juga dikenal dengan methylthioninium klorida yang merupakan salah satu zat warna thiazine, digunakan karena harganya ekonomis, mudah diperoleh dan zat penting dalam proses pewarnaan kulit kain mori dan kain katun. Penggunaan methylene blue dapat menimbulkan beberapa efek seperti iritasi saluran pencernaan jika tertelan menimbulkan sianosis jika terhirup dan iritasi pada kulit jika tersentuh oleh kulit [8]. Stuktur methylene blue dapat dilihat pada Gambar 1.

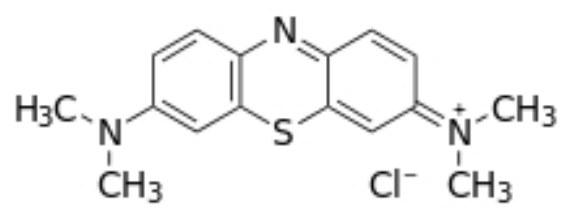

Gambar 1. Struktur Methylene Blue [1]- [9]

\section{Aktivasi}

Aktivasi adalah suatu perubahan fisika dimana luas permukaan karbon menjadi lebih besar karena hidrokarbon yang menyumbat pori-pori terbebaskan. Ada 2 cara untuk melakukan proses aktivasi yaitu aktivasi secara fisika (thermal) dan aktivasi kimia. 
Perlakuan dengan $\mathrm{NaOH}$ akan menurunkan tingkat kristalinitas abu layang. Abu layang yang semakin amorf ini (tingkat kristalinitasnya rendah) mempunyai kemampuan absorbsi logam yang semakin tinggi [10]. Aktivasi dapat juga dilakukan menggunakan basa yaitu $\mathrm{NaOH}$ dengan memvariasikan konsentrasi 5, 10 dan 15\% terhadap arang aktif cangkang kemiri [11].

\section{Penjerapan Methylene Blue}

Penjerapan larutan methyl violet menggunakan abu kayu hasil pembakaran coto makassar bertujuan mengurangi kadar methylene blue dalam larutan sehingga jika diaplikasi di lingkungan mampu menangani pencemaran lingkungan. Adsorpsi ini juga untuk mengetahui kinerja adsorben abu kayu. Proses penjerapan dilakukan dengan memasukkan abu kayu ke dalam larutan methylene sesuai kosentrasi yang ditentukan kemudian dishaker dengan kecepatan skala 4 pada suhu kamar hingga tercapai kesetimbangan, selanjutnya disaring. Filtrat dianalisis kadar methylene blue dengan mengukur absorbansinya menggunakan spektrometer pada panjang gelombang $664 \mathrm{~nm}$. Persen penjerapan dihitung dengan menggunakan Persamaan (1).

$$
\mathrm{Ps}=\left|\frac{(\cos -20)}{(\cos )}\right| x \mathrm{100 \%}
$$

Keterangan :

$\mathrm{Co}=$ Kosentrasi awal methylene Blue $(\mathrm{mg} / \mathrm{L})$

$\mathrm{Ce}=$ Kosentrasi methylene Blue pada kesetimbangan $(\mathrm{mg} / \mathrm{L})$

PS $=$ Persen penjerapan $(\%)$

Kapasitas maksimum adsorpsi dihitung berdasarkan model Isotherm Langmuir yang ditunjukkan pada Persamaan (2). Persamaan Langmuir dikemukakan oleh [11]

$$
\mathrm{qe}=\frac{i \mathrm{~m} E c_{\mathrm{s}}}{-+i c_{\mathrm{c}}}
$$

Jumlah pengotor yang terjerap tiap massa adsorben pada kesetimbangan dihitung menggunakan persamaan (3).

$$
\mathrm{q} e=\frac{c u-c}{\mathrm{~m}} \times \mathrm{va}
$$

Persamaan (2) dilinierkan menjadi :

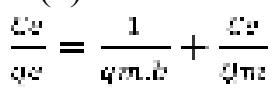

keterangan

qe = Jumlah konsentrasi methylene blue terjerap tiap satuan massa kesetimbangan $(\mathrm{mg} / \mathrm{g})$

$\mathrm{qm}=$ Kapasitas adsorpsi monolayer $(\mathrm{mg} / \mathrm{g})$

$\mathrm{b}=$ Konstanta adsorpsi (L/mg)

$\mathrm{Va}=$ Volume adsorbat $(\mathrm{mL})$

\section{Metode Penelitian}

Penelitian terdiri dari aktivasi dan adsorpsi methylene blue serta penentuan kapasitas adsorpsi maksimum (qm) abu.

\section{A. Aktivasi}

a. Aktivasi Basah $(\mathrm{NaOH})$

Aktivasi dilakukan dengan menimbang 50 gr abu ditambahkan $500 \mathrm{ml} \mathrm{NaOH} 3 \mathrm{M}$ dan diaduk pada kecepatan 500 rmp selama 3 jam suhu $40^{\circ} \mathrm{C}$ selanjutnya dicuci hingga $\mathrm{pH} 7$ dikeringkan hingga kadar air 10\%.

\section{b. Aktivasi $\mathrm{NaCl}$}

50 gram abu ditambahkan $500 \mathrm{ml} \mathrm{NaCl} 0.85$ M dishaker kecepatan $500 \mathrm{rpm}$ selama 24, disaring dan dicuci hingga $\mathrm{pH}$ filtrat 7. Proses selanjutnya dikeringkan sampai kadar air 10\% dan siap diaplikasikan.

B. Adsorpsi

Proses adsorpsi dilakukan dengan menimbang 0.25 abu kemudian dimasukkan ke erlemeyer dengan kosentrasi masing erlemeyer 10, 20, 30, 40 dan $50 \mathrm{ppm}$ sebanyak $50 \mathrm{ml}$. Erlemeyer selanjutnya di shaker selama 1.5 jam kemudian disaring, filtrat diukur absorbansi menggunakan UV-VIS.

\section{Kapasitas Adsorpsi}

Kemampuan adsorben menjerap adsorbat dihitung menggunakan Persamaan Langmuir. Linerisasi ditunjukkan Persamaan (4) didapatkan kapasitas maksimum adsorpsi (qM). 


\section{Hasil Dan Pembahasan}

\section{A. Kurva Standar}

Penentuan konsentrasi methylene blue baik sebelum (Co) dan setelah adsorpsi pada keadaan setimbang (Ce) diukur menggunakan UV-VIS. Besarnya nilai Co dan Ce dapat diketahui dengan mengetahui nilai absorbansi. Persamaan Lambergen dapat mengkonversi absorbansi ke konsentrasi. Penentuan persamaan dibuat dengan menghubungkan konsentrasi standar terhadap absorbansi, sehingga tahap pertama yakni pembuatan kurva standar seperti pada Gambar 2.

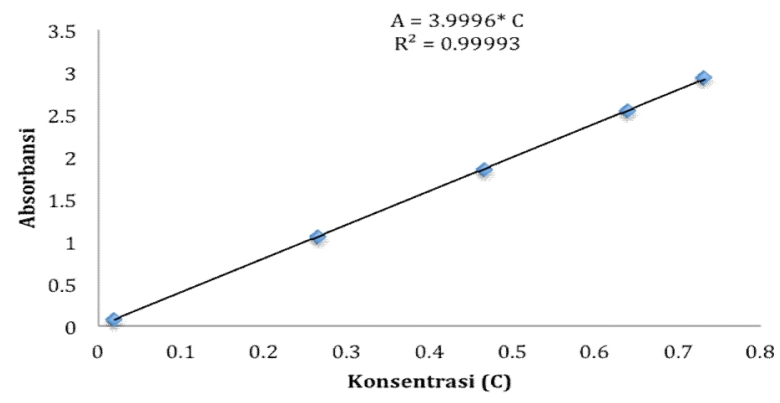

Gambar. 2 Kurva Standar

Hubungan konsentrasi terhadap absorbansi didapatkan $\mathrm{A}=3.9996^{*} \mathrm{C}$ yang merupakan persamaan lambergen. Nilai absorbansi diukur menggunakan UV-VIS kemudian dikonversi menggunakan $\mathrm{C}=\mathrm{A} / 3.9996$ didapatkan selanjutnya Ce tiap sample pengujian.

\section{B. Pengujian}

Adsorpsi methylene blue menggunakan abu masak air minum dan ACM tanpa aktivasi maupun aktivasi serta abu masak air (AMA) sebanyak masing masing 0.25 gram ke dalam ke lima variasi konsentrasi selama 1.5 jam dengan kecepatan shaker $500 \mathrm{rpm}$. Konsentrasi kesetimbangan (Ce) terhadap jumlah methylene blue terjerap persatuan massa adsorben (qe) menggunakan Persamaan (3). Adsrorpsi ACM dan AMA ditunjukkan Gambar 3 dan ilustrasi jumlah terserap pada Gambar 4.

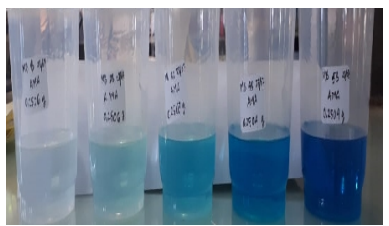

a. Adsorpsi AMA Blue

Adsorpsi ACM lebih memiliki jumlah terserap lebih tinggi dibandingkan AMA dan terlihat pada Gambar 3 bahwa Ce lebih rendah yang mengindikasikan bahwa kemampuan penjeraannya lebih besar dibandingkan abu masak air.

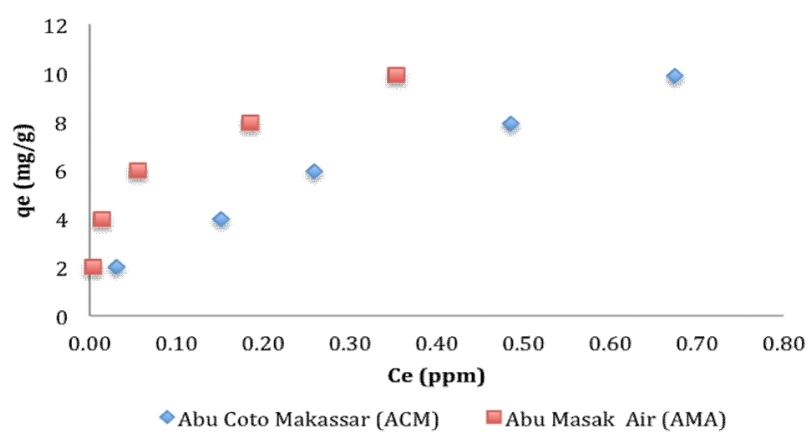

Gambar 4. Hubungan Ce Terhadap qe ACM Dan AMA

Konsentrasi setimbang (Ce) methylene blue pada AMA lebih rendah dan qe lebih besar dibandingkan ACM. Hal ini terlihat ketika adsorpsi yakni abu masak air penjerap didasarkan pada pori adsorben sedangkan pada ACM terjadi di permukaan ditunjukkan dengan terjadinya perubahan warna abu tersebut. Adsorben ACM mengindikasikan selain penjerapan melalui pori, adsorpsi juga terjadi akibat ikatan kimia pada permukaan ditunjukkan warna menjadi kebiruan atau biru muda. Tingginya komposisi $\mathrm{Ca}$ pada ACM salah satu indikator ikatan kimia permukaan adsorben terhadap methylene blue. Pada AMA yakni komposisi Si yang tinggi menyebab pori lebih banyak dan besar karena memiliki ukuran partikel lebih sehingga pori juga besar selain itu adanya Al juga meingkatkan kemampuan penjerapan [11]. 


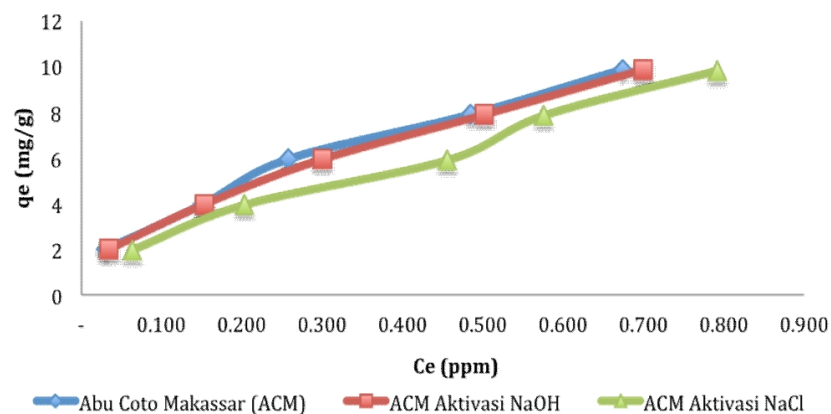

Gambar 4. Hubungan Ce Terhadap qe ACM Tanpa Aktivasi dan ACM Aktivasi $\mathrm{NaOH}$ dan $\mathrm{NaCl}$

AMA tanpa aktivasi dan aktivasi baik $\mathrm{NaOH}$ memiliki nilai qe berimpit meskipun $\mathrm{Ce}$ berbeda. ACM aktivitasi $\mathrm{NaCl}$ kecenderungan sama namun ketika konsentrasi 30, 40 dan 50 ppm nilai qe lebih rendah dibanding keduanya. Hal ini mengindikasikan bahwa kemampuan penjerapan masih membutuhkan waktu hingga tercapai kesetimbangan ditunjukkan masih linier dan tajam. Posisi fase satsioner belum ditunjukkan pada gambar 4 untuk ketiga adsorben tetapi pada ACM dan ACM Aktivasi $\mathrm{NaOH}$ kemiringan atau slope lebih landai dan mengarah proses stabil dan tetap. Keadaan ini berbeda dengan $\mathrm{ACM}$ aktivasi $\mathrm{NaCl}$ dengan kemiringan yang tajam menunjukkan waktu ke kondisi stabil membutuhkan waktu lebih lama dibanding kedua adsorben. Kecenderungan ini menunjukkan bahwa kemampuan penjerapannya lebih besar yang ditunjukkan dengan menghitung qm menggunakan persamaan (4).

\section{Kapasitas Maksimum Adsorpsi (qm)}

Kapasitas adsorpsi (qm) ditentukan linierisasi Persamaan (2) yakni hubungan ce/qe terhadap ce. Hubungan keduanya dibuat grafik dan diselesaikan secara regresi linier maupun numerik.

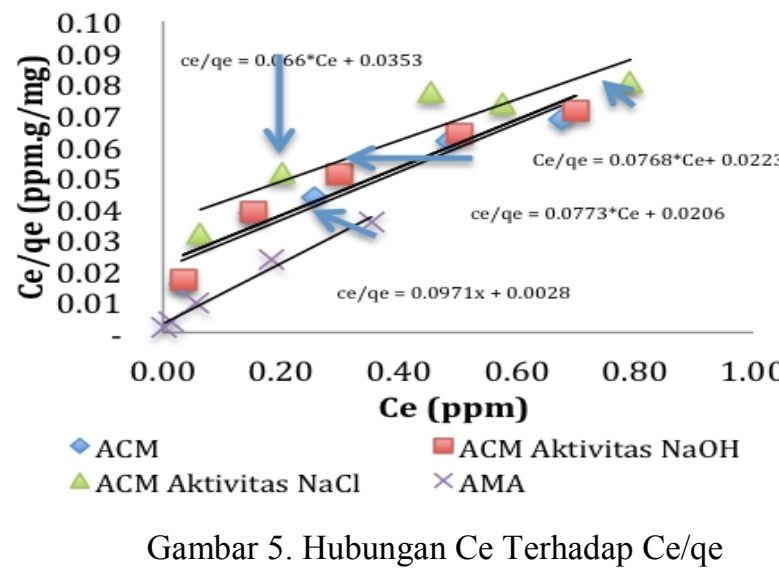

Persamaan ce/qe $=0.066^{*} \mathrm{Ce}+0.0353$ seperti pada Gambar 5 untuk ACM aktivasi $\mathrm{NaCl} 0.85 \mathrm{M}$. Nilai qm didapatkan dari 1/slope yakni 1/0.066 sebesar 15.15 ppm.g/mg. Kapasitas adsorpsi adsorben ACM, ACM Aktivasi $\mathrm{NaOH}$ dan AMA ditunjukkan Tabel 2.

Tabel 2. Kapasitas Adsorpsi Maksimum

\begin{tabular}{clc}
\hline No & Nama Sampel & $\begin{array}{c}\text { Kapasitas } \\
\text { Maksimum } \\
\text { Adsorpsi (qm) }\end{array}$ \\
\hline 1 & AMA & 10.29 \\
2 & ACM & 12.93 \\
3 & ACM NaOH $3 \mathrm{M}$ & 13.01 \\
4 & ACM NaCl 0.85 M & 15.15 \\
\hline
\end{tabular}

Keterangan :

AMA $=$ Abu Masak Air

$\mathrm{ACM}=\mathrm{Abu}$ Coto Makassar

Kapasitas maksimum adsorpsi (qm) ACM lebih tinggi dari AMA selain itu kinerja meningkat melalui aktivasi baik $\mathrm{NaOH}$ maupun $\mathrm{NaCl}$. Proses aktivasi bertujuan membersihkan permukaan dan membuka pori yang menutupinya dengan menggunakan kedua bahan. Aktivasi $\mathrm{NaCl}$ memiliki nilai qm lebih tinggi dibandingkan lainnya yang selanjutnya akan dilakukan penelitian lebih lanjut. Penilitian serupa pada proses adsorpsi $\mathrm{Cu}^{2+}$ menggunakan karbon aktivasi $\mathrm{NaOH}$ $1 \%$ menunjukan peningkatan penjerapan sebesar $80.87 \%$ dibandingkan tanpa aktivasi [12] . 


\section{Kesimpulan}

1. ACM dan AMA memiliki kemampuan Adsorben

2. Aktivasi meningkatkan qm adsorben

3. Kapasitas adsorpsi maksimum (qm) ACM 12.37 $\mathrm{mg} / \mathrm{g}$ dan sebesar dan AMA yaitu 10.29 mg/g. Aktivasi ACM NaOH 3M memiliki kapasitas adsorpsi (qm) sebesar $13.01 \mathrm{mg} / \mathrm{g}$ dan aktivasi $\mathrm{NaCl} 0.85 \mathrm{M}$ yaitu $15.15 \mathrm{mg} / \mathrm{g}$.

\section{Ucapan Terima Kasih}

Terima kasih kepada civitas jurusan teknik kimia, Politeknik Negeri Ujung Pandang atas pendanaan serta tim riset dan Irwan Mahardika atas bantuan analisis XRD.

\section{Daftar Pustaka}

[1] Yuliani HR. 2012. "Asdorpsi Methyl Violet Menggunakan Kalembang Teraktivasi”. Prosiding Seminar Keteknitan Universitas Mulawarman 2012. Samarinda.

[2] Purawisastra, S. 2011. Penggunaan beberapa jenis abu untuk isolasi senyawa galaktomanan dari ampas kelapa. Jurnal Riset Teknologi Pencegahan Pencemaran Industri. 1(4) : 260-266.

[3] Anggoro, D.D. 2005 Aktifitas dan pemodelan katalis silikat dari abu sekam padi untuk konveksi hexana. Reaktor 9(1):17.
[4] Nada., I., M dan Suryatama, I.B, 2016, Karakteristik Fisik Campuran Batu Bata Dengan Memanfaatkan Abu Sisa Pembakaran Limbah Kayu, Jurnal Kurva Teknik, Univesitas Maharespati Denpasar, Indonesia.

[5] Yuliani HR, 2019, “Analisis XRD”, PT. Semen Tonasa, Pangkep.

[6] Simpen, N.I, 2001, Preparasi dan karakterisasi lempung montmorilonit teraktivasi asam terpilar TiO2, Tesis S2 Ilmu Kimia, UGM, Yogyakarta.

[7] Derakhshan, Z., Baghapour, M. A., Ranjbar, M., \& Faramarzian, M. (2013). Adsorption of methylene blue dye from aqueous solutions by modified pumice stone: kinetics and equilibrium studies. Health Scope , 136-44.

[8] Tan, I. A., Ahmad, A. L., \& Hameed, B. (2007). Adsorption of basic dye on high surface area activated carbon prepared from coconut husk: equilibrium, kinetic and thermodynamic studies. Journal of Hazardous Materials , 337-346.

[9] Knaebel, K.S., 2008, Adsorbent Selection, Adsorption Research, Inc, Dublin, Ohio.

[10] Sumarni, Noor Hindryawati, Alimuddin, Aktivasi Dan Karakterisasi Zeolit Alam Menggunakan Naoh Activaton And Characterization Of Natural Zeolite Using $\mathrm{NaOH}$, Jurnal Atomik., 2018, 03 (2) Hal 106-110

[11] Maulana. G.G.R, Agustina I.Y dan Susi, 2017, Proses Aktivasi Arang Aktiv Dari Cangkang Kemiri Dengan Variais Jenis Dan Kosentrasi Activator Kimia, Ziraa'ah Vol. 42 No 3, 2017. P. 247-256.

[12] Wulandari Futri, Umiatin, Esmar Budi, Pengaruh Konsentrasi Larutan Naoh Pada Karbon Aktif Tempurung Kelapa Untuk Adsorpsi Logam $\mathrm{Cu}^{2+}$ : Jurnal Fisika Dan Aplikasinya, Vol. 16, No. 2, Oktober 201560 